


Original Article

\title{
Factors Affecting Group Size and Vigilance Behaviour of Maasai Giraffe (Giraffa camelopardalis tippelskirchi) on the Serengeti-Ngorongoro Ecosystem, Tanzania
}

\author{
Dr. Wilfred N. Marealle ${ }^{1 *}$, Dr. Tomas Holmern ${ }^{2} \&$ Dr. Eivin Røskaft ${ }^{3}$ \\ ${ }^{1}$ Tanzania Wildlife Research Institute, Tanzania. \\ ${ }^{2}$ Norwegian Environment Agency, Norway. \\ ${ }^{3}$ Department of Biology, Norwegian University of Science and Technology, NTNU, NO-7091 Trondheim, Norway. \\ *Author for Correspondence email: marealle@bio.ntnu.no
}

Article DOI: https://doi.org/10.37284/eajenr.2.1.133

\section{Article history:}

Received: 28 Aug 2019

Accepted: 17 Sep 2019

Published: 08 Apr 2020

Keywords:

Maasai Giraffe,

Vigilance,

Serengeti,

Ngorongoro,

Group Size,

Ecosystem.

\begin{abstract}
This study investigated the factors affecting different group sizes of Maasai giraffe (Giraffa camelopardalis tippelskirchi) in the Serengeti-Ngorongoro ecosystem. The study was motivated to test the following hypotheses: 1) in a given group, the sex ratio of males to females with calves is related to group size; 2) group size affects vigilance behaviour; 3) illegal hunting influences group size and vigilance behaviour; and 4) group size differs in different habitats, being larger in woodlands during the wet season and in riverine habitats during the dry season. A negative relationship between the ratio of the proportion of adult males to females with calves and group size was observed, whereas the proportion of females and calves increased with group size. The proportion of vigilant individuals decreased with an increase in group size. Habitat, risk of illegal hunting and proportion of calves in the group was found to be significant contributors to an increase in vigilance behaviour. However, the results do not support the hypotheses that seasonality and habitat preference affect group sizes of the Maasai giraffes. Emphasis should be put on antipoaching efforts on males and nursery groups, especially in areas with a high risk of illegal activities.
\end{abstract}

\section{APA CITATION}

Marealle, W., Holmern, T., \& Røskaft, E. (2020). Factors Affecting Group Size and Vigilance Behaviour of Maasai Giraffe (Giraffa camelopardalis tippelskirchi) on the Serengeti-Ngorongoro Ecosystem, Tanzania. East African Journal of Environment and Natural Resources, 2(1), 14-23. https://doi.org/10.37284/eajenr.2.1.133. 


\section{CHICAGO CITATION}

Marealle, Wilfred, Tomas Holmern, and Eivin Røskaft. 2020. "Factors Affecting Group Size and Vigilance Behaviour of Maasai Giraffe (Giraffa Camelopardalis Tippelskirchi) on the Serengeti-Ngorongoro Ecosystem, Tanzania". East African Journal of Environment and Natural Resources 2 (1), 14-23. https://doi.org/10.37284/eajenr.2.1.133.

\section{HARVARD CITATION}

Marealle, W., Holmern, T. and Røskaft, E. (2020) "Factors Affecting Group Size and Vigilance Behaviour of Maasai Giraffe (Giraffa camelopardalis tippelskirchi) on the Serengeti-Ngorongoro Ecosystem, Tanzania", East African Journal of Environment and Natural Resources, 2(1), pp. 14-23. doi: 10.37284/eajenr.2.1.133.

\section{IEEE CITATION}

W. Marealle, T. Holmern, and E. Røskaft, "Factors Affecting Group Size and Vigilance Behaviour of Maasai Giraffe (Giraffa camelopardalis tippelskirchi) on the Serengeti-Ngorongoro Ecosystem, Tanzania", EAJENR, vol. 2, no. 1, pp. 14-23, Apr. 2020.

\section{MLA CITATION}

Marealle, Wilfred, Tomas Holmern, and Eivin Røskaft. "Factors Affecting Group Size and Vigilance Behaviour of Maasai Giraffe (Giraffa Camelopardalis Tippelskirchi) on the Serengeti-Ngorongoro Ecosystem, Tanzania". East African Journal of Environment and Natural Resources, Vol. 2, no. 1, Apr. 2020, pp. 14-23, doi:10.37284/eajenr.2.1.133.

\section{INTRODUCTION}

Living in groups is a common phenomenon in many animal species; some herbivores form herds, some fish species form schools, many birds live in colonies and some animals live in large, extended family groups (Krebs, 2009). Animal groups vary greatly in both size and complexity. There are different group structures such as aggregations for specific activities (e.g., feeding, breeding) and stable family groups (e.g., clear hierarchies and organisations) (Krause \& Ruxton, 2002; Brewer, 2008). A group's size varies through time which is evident in many species (Pulliam \& Caraco, 1984). Seasonal variations in rainfall and consequently in plant productivity induce large temporal variations in the group sizes of some African ungulates (Sorensen \& Taylor, 1995; Bergström \& Skarpe, 1999).

How a species comes to live in groups and group size is formed depends upon the evolutionary advantages associated with living in groups. This includes but not limited to having many eyes or collective detection. For instance, predator detection becomes increasingly effective as group size increases (Ebensperger et al., 2006). Aggregation by prey species causing a 'dilution effect' as well as mobbing behaviour function can be anti-predator mechanisms (Berger, 1979; Reynolds, 1983; Pulliam \& Caraco, 1984; Caro, 2005). Mating and reproductive success are frequently considered to be higher in animals living in groups as found in the "lek" system in Ugandan kob (Kobus kob thomasi), Kafue lechwe (Kobus leche kafuensis), and Topi (Damaliscus korrigum). This allows for mate choice for "'good genes" by females (Buechner \& Roth, 1974; Nefdt \& Thirgood, 1997; Bro-Jorgensen \& Durant, 2003).

Conversely, living in groups can be disadvantageous (König, 1997). For instance, living in groups considerably increases the risk of predation (Lian et al., 2007) because it is easier for a predator to detect a group of individuals than a single one. Thus, there are different optimal group sizes for different species. Animals in groups are also at risk of being exploited by other members of the group; this is particularly true in groups with dominance hierarchies (Cant et al., 2006; Mathot \& Giraldeau, 2010). For example, mating is paramount for all individuals, but it is important not to mate with individuals that are genetically closely related (Day et al., 2003; Charlesworth \& Willis, 2009). Social organisation including the size and composition of social groups and mating systems influences host proximity (Ezenwa, 2004). This is because the number and duration of contacts in a population result in a higher risk of the spread of diseases in animals living in groups than among solitary animals (Krause \& Ruxton, 2002). For instance, diseases such as anthrax and rinderpest almost wiped out populations of impala and buffalo (Syncerus caffer), accounting for $90 \%$ and $20 \%$ of mortality in impala and buffalo groups, respectively in the Lake Manyara National Park, northern Tanzania during the late 1950s and massive deaths 
in Serengeti ecosystem in the 1960s (Prins \& Weyerhaeuser, 1987; Buhalis, 2000).

There have been several observational studies on individual Maasai giraffes (Giraffa camelopardalis tippelskirchi), but their social systems have not been described adequately (van der Jeugd \& Prins, 2000). No study on the Maasai giraffe group sizes, vigilant behaviour, or habitat preference has been conducted on a large scale in Serengeti National Park (SNP) or Ngorongoro Conservation Area (NCA) in Tanzania. Therefore, this study aimed to explore the behavioural and social characteristics that sustain giraffes' ecological and biological requirements. Male and female ungulates often exhibit spatial segregation. In giraffes, sex ratio and feeding ecology both vary with habitat; males are more common in forests with taller and thicker vegetation, whereas females are more common in open habitats (Young \& Isbell, 1991; Ginnett \& Demment, 1997).

This study tested four hypotheses; $\mathrm{H}_{1}$, in a given group, the sex ratio of males to females with calves is related to group size where the ratio of males decreases with group size, while the frequency of females with calves increase with group size. $\mathrm{H}_{2}$, group size affects the vigilance behaviour in that number of vigilant individuals increases with group size while the frequency of vigilant individuals decreases with group size (Okello et al., 2008; Philipo, 2011; Kimwaga, 2014). $\mathrm{H}_{3}$, illegal hunting influences group size and vigilance behaviour in that individuals are more vigilant in illegal hunting areas while group sizes are smaller (Marealle et al., 2010). $\mathrm{H}_{4}$, studies carried out by Leuthold and Leuthold (2012) and (1997) reported that giraffes' habitat preferences vary with seasons (wet/dry) group size differs in different habitats, being larger in woodlands during the wet season and in riverine habitats during the dry season.

\section{MATERIALS AND METHODS}

\section{Study Area}

The Serengeti ecosystem covers an area of 25,000 $\mathrm{km}^{2}$ on the border of Tanzania and Kenya, East Africa $\left(1^{\circ} 15^{\prime}\right.$ to $3^{\circ} 30^{\prime} \mathrm{S}, 34^{\circ}$ to $36^{\circ} \mathrm{E}$ ) (see Figure 1, in Marealle et al., 2010). The Crater Highlands and the Rift Valley form the eastern boundary; the
Western Corridor stretches west to Lake Victoria and forms the western boundary. The remainder of the western boundary is established by dense cultivation. The Isuria Escarpments and Loita Plains in Kenya form the northern boundary. The ecosystem covers several different conservation administrations (Arcese \& Sinclair, 1995).

The mean temperatures vary between $15^{\circ} \mathrm{C}$ to $25^{\circ}$ $\mathrm{C}$; the area experiences a bimodal rainfall pattern with long rains during March-May and short rains in November-January which ranging from 500 $\mathrm{mm} / \mathrm{yr}$ in the southern dry plains to $1,200 \mathrm{~mm} / \mathrm{yr}$ in the wet northwest (Sinclair \& Arcese, 1995). The ecosystem is not only the home of the largest herds of migratory ungulates but also supports approximately 70 larger mammal species and some 500 avifauna species (Sinclair \& Arcese, 1995; Kideghesho et al., 2007). The Serengeti contains a range of vegetation types where the northern sections are characterised by rolling, wooded savannah; south-eastern parts features almost treeless plains; the western corridor is a wooded region mostly covered by the savannah woodland, while further to the east, the terrain rises steeply to massif highlands and forested areas (Kideghesho et al., 2006; Magige, 2008).

\section{Study Species}

Maasai giraffe is described as a non-territorial ungulate, moving without a specific leader or coordination of herd movements (Owen-Smith, 1988; Ginnett \& Demment, 1997; van der Jeugd \& Prins, 2000; Marealle et al., 2010). The Maasai giraffe remains widespread with a total population of more than 100,000 individuals and the IUCN red list categorises them as "least concerned" species (Fennessy \& Brown, 2010). Nevertheless, recent preliminary population estimate suggests that a decline in the total population has taken place (Fennessy \& Brown, 2010). Giraffes are preyed by both lions (Panthera leo) and spotted hyenas (Crocuta crocuta) (Hayward \& Kerley, 2005; Bercovitch \& Berry, 2010).

\section{Field Methods}

Fixed transects were driven on a monthly basis from 6.30 AM and 6.30 PM, covering a total distance of $11,172 \mathrm{~km}$. Existing major roads inside 
the SNP were used as transects because cutting of new roads is prohibited; off-road driving was done only when it was necessary because of dense vegetation and rugged terrain (Okello \& Yerian, 2009). The study area was divided into two areas, according to the threat of illegal hunting to provide a detailed picture of group sizes (Figure 1; Marealle et al., 2010). This categorisation took into account human disturbances such as illegal hunting (Okello \& Yerian, 2009; Marealle et al., 2010).

\section{Group Size and Behaviour}

In this study, a group of giraffes was defined by any number of giraffes behaving in a coordinated manner either moving together in the same direction or engaged in the same activity at any one time within a distance of $200 \mathrm{~m}$ to $1000 \mathrm{~m}$ (van der Jeugd \& Prins, 2000; Cameron \& Du Toit, 2005).

A small degree of double counting was impossible to avoid, but the large total sample size $(>2000$ individuals, 581 groups) minimised this problem. The risk of recording the same giraffe group twice was avoided by the use of photographs (Marealle et al., 2010). For each observed group, the number of individuals, the sex of each individual and the habitat they were found were recorded. In addition, for each encountered group, we recorded its initial activity following the methods described in (Okello \& Yerian, 2009; Marealle et al., 2010).

Vigilance in the study referred to the time giraffes refrained from any other activities, actively scanning the surrounding environment by standing still, stretching their necks with their heads up. When individuals or group sighted the initial activity was recorded and five minutes were spent to assess overall activities and members associations. In the analysis, vigilance proportion in a group, the ratio of the number of vigilant individuals $\left(\mathrm{N}_{\mathrm{V}}\right)$ within a group divided by the number of all individuals in a group $\left(\mathrm{N}_{\mathrm{G}}\right)$ was used.

In some of the analysis, the groups were recategorised into four major group size categories 1 (group size $=1$ individual), $2($ group size $=2-5$ individuals), 3 (group size $=6-10$ individuals) and 4 (group size $=11-30$ individuals). When using the categorised data we refer to it as pooled data.

\section{Sex and Age Classification}

The sex of the giraffes was determined by observing the genitalia and antlers (Pratt \& Anderson, 1979; Pratt \& Anderson, 1982; Pratt \& Anderson, 1985; Young \& Isbell, 1991; van der Jeugd \& Prins, 2000). In cases of poor visibility, a pair of binoculars was used and in cases where it was not possible to ascertain the sexes of an individual, that individual was recorded as "unknown". Age was estimated as a percentage of an adult's individual height (4.5-5.5 m); a criterion to assign the ages of individuals was created into the following classes: calf (10-40\% of adult size), young (50-60 \% of adult size), sub-adult (70-80\% of adult size), and adult (90-100\% of adult size). During analyses, all individuals of about $10-60 \%$ as calves and the remaining 70-100 as adults were pooled together.

\section{Habitat Classification and Seasons}

Vegetation was categorised into two types: one, the woodland (i.e., dense woodland consisting of Acacia trees) and second, open landscapes (i.e., everything from open woodland to bushland to open grassland). The overall year was classified into two main seasons, wet and dry. The wet season was the period of excessive rainfall starting from November to May and dry season was the period between June to October.

\section{Statistical Analyses}

SPSS version 21.0 for Windows was used to analyse the data. Non-parametric statistical tests were used where the data was not normally distributed. Chi-square tests were employed to test the effects of illegal hunting, habitat, season, vigilance behaviour, and sexual composition on group size in Maasai giraffes. Finally, linear regression analyses were used to test the importance of each of these variables at a significance level of $p<0.05$.

\section{RESULTS}

\section{Group Size and Sex Composition}

The researchers were able to sight 581 groups of giraffes along the driven transects during the study 
period (Figure 1) including singletons (1 individual) and groups of up to 30 individuals. Most of the singleton groups were formed by males (Figure 2). The median group size was two individuals and the mean group size was $2.2( \pm 0.9$ $\mathrm{SD})$. When the singletons were excluded, the median and mean group size was 5.43 and 4 respectively (Figure 2).

Overall, 2,929 individuals were observed with the highest percentage being of females $(62.5 \%)$ than males (37.5\%) (see also Marealle et al. 2010). The majority of giraffe groups ranged in size from 1 to 10 individuals $(88.4 \%, N=581)$. The most common group sizes were 2-5 individuals $44.4 \%$ $(N=258)$, followed by 6-10 individuals $22.4 \%(N$ $=130)$ and singletons $22 \%(N=128$,$) . Only 11.2$ $\%(N=65)$ of the groups consisted of 11-30 individuals.

There were no statistically significant effects of habitat $\left(\chi^{2}=4.82\right.$, df $\left.=3, p=0.185\right)$, season $\left(\chi^{2}=\right.$ $4.13, \mathrm{df}=3, p=0.248)$ or risk of illegal hunting $\left(\chi^{2}\right.$ $=4.78, \mathrm{df}=3, p=0.189$ ) on group size (pooled data).

The proportion of males decreased with group size whereas the proportion of females and calves increased with group size (Figure 3). A linear regression using group size (pooled group data) as the dependent variable and proportion of males, females and calves as independent variables proved statistically significant. These variables explained $8.5 \%$ of the variation in the group size $\left(\mathrm{r}^{2}=0.085\right.$, $p<0.001)$. The most important variable explaining variation in the group size in the linear regression analysis was the proportion of calves $(\mathrm{t}=4.24, p<$ $0.0001)$. The proportion of females added a significant value to this variable $(\mathrm{t}=1.96, p=$ $0.050)$, whereas the proportion of males did not $(\mathrm{t}=$ $0.041, p=0.968)$.

\section{Group Size and Vigilance Behaviour}

There was a statistically significant positive correlation between group size (all groups) and number of vigilant individuals (Pearson $\mathrm{r}=0.172$, $N=581, p=0.001$ ). Although the proportion of vigilant individuals decreased with group size $(\mathrm{r}=$ -0.093, $N=508, p=0.037$ ). However, the proportion of vigilant individuals depended highly on the number of vigilant individuals in any group
( $\mathrm{r}=0.694, N=509, p<0.001)$. There was no significant correlation between proportions of females (Pearson $\mathrm{r}=0.093, N=108, p=0.340$ ) or proportion of males (Pearson $\mathrm{r}=-0.134, N=109, p$ $=0.166)$ with group size. The proportion of vigilant females showed a strong negative correlation with the proportion of vigilant males (Partial correlation controlling for group size; $\mathrm{r}=-0.434, N=103, p<$ $0.001)$ indicating that whenever the proportion of vigilant members of one sex increases, the proportion of vigilant members of the other sex decreased.

\section{Vigilance, Habitat, Season and Risk of illegal hunting}

A linear regression analysis examining the variation in the proportion of vigilant individuals ( 0 to 1$)$ as a dependent variable was tested with seven independent variables (Table 1). However, only four of them proved to be significant contributors to the variation in the proportion of vigilant individuals, altogether explaining $7.4 \%$ of this variation. The variable explaining most of the variation in the proportion of vigilance was the habitat was more vigilance in woodland. The second most important predictor was the risk of illegal hunting was more vigilance in high-risk areas. The proportion of calves in a group and group size (all groups) were the third and fourth predictors, respectively in explaining the variation. The other three independent variables; seasons, the proportion of males in the group and the proportion of females in the group were insignificant (Table 1).

\section{DISCUSSION}

During the study, 581 groups of giraffes $(2,929$ individuals) were observed and recorded from singletons (1 individual) up to the largest group of 30 individuals. Majority of groups observed were in the range of 1 to 10 individuals $(88.8 \%)$. The average group size was 2.2 individuals, which is similar to previous studies (van der Jeugd \& Prins, 2000; Bercovitch \& Berry, 2010). There were more females $(62.1 \%)$ than males $(37.3 \%)$ and only a few $(0.9 \%)$ individuals (mostly calves) were not sexed because of inaccessibility or immediate flight when followed by the researchers (Marealle et al., 2010). 
The proportion of males was found to be highest in groups of one individual. In groups of 2-4 individuals, the proportions of females and calves gradually increased whereas the proportion of males decreased. This result is in support of the first hypothesis that there are more females and calves in larger groups. Weak/lose inter-individual relationships and few preferential associations between giraffe age and sex classes have been previously reported (Owen-Smith, 1988; Ginnett \& Demment, 1997; Breedlove, 2004). Sexual segregation may explain the weak relationship because sexually dimorphic ungulates have been reported to form sexually segregating groups. There are several hypotheses that have tried to explain sexual segregation in polygynous dimorphic species. The "Differences in activity patterns hypothesis" Loe et. al. (2006) may be the reason behind the unequal proportion of males-femalescalves in a group. This because males are solitary wanderers hence, they are always in search of oestrous females (van der Jeugd \& Prins, 2000; Bercovitch et al., 2006).

Many social and environmental factors influence vigilance including sex, predation risk and group size (Li et al., 2009). Vigilance has been implicated as playing an important role in giraffe behaviour, potentially contributing to the maintenance of sexual segregation in foraging heights (Young \& Isbell, 1991; Ginnett \& Demment, 1997; Cameron $\&$ Du Toit, 2005). The relationship between group size and the proportion of vigilant individuals in this study was found to support the second hypothesis in which an increase in the group size resulted in a decrease in the proportion of vigilant individuals.

Vigilance was observed to be higher when the proportion of females with calves was high, this was also found by Pratt and Anderson (1979). Predation may be a fundamental cause for the increased in vigilance in this case, as $50-70 \%$ of giraffe calves in their first year of life ended up as victims of predation especially to lions (OwenSmith, 2008; Bercovitch \& Berry, 2010). Furthermore, it was observed that males were less vigilant when together with females as the proportion of vigilant males and females correlated negatively. The reason for this might be that male giraffes were basically focused on mating opportunities when together with females. Although the proportion of vigilant individuals decreased with group size, the number of vigilant individuals still correlated significantly with group size. According to Cameron and du Toit (2005), a probable explanation for the increased vigilance in larger groups is that males are absent from large groups which is an avoidance of same-sex aggression from conspecifics and the maintenance of dominance among males.

Illegal hunting poses a threat to wildlife populations in SNP and is one of the biggest conservationhuman-wildlife conflicts in the area (Holmern et al., 2004; Kaltenborn et al., 2005; Holmern et al., 2006; Ndibalema \& Songorwa, 2007; Okello \& Yerian, 2009). Many studies on vigilance behaviour in ungulates have focused on predation (Lima, 1995; Beauchamp, 2003; Okello et al., 2008; Bercovitch \& Berry, 2010; Periquet et al., 2010). However, the present study investigated the effect of illegal hunting on vigilance behaviour and group size as well. Just as with increased predation risk, increasing threats of illegal hunting (high-risk areas) led to an increase in the proportion of vigilant individuals in the group. Giraffes found in areas most severely affected by illegal hunting (the northwest and western parts of the Western Corridor) were more alert and fled farther away when approached (Marealle et al., 2010). This partially also supports the third hypothesis as group sizes were not affected by the risk of illegal hunting but rather that they were more vigilant in risk-prone areas. Such risk-prone areas are areas with high risk of illegal hunting and woodlands. Similar to an earlier study by van der Jeugd and Prins (2000), this study did not find any significant differences in giraffe group size between seasons, which does not support our fourth hypothesis.

Habitat also plays an important role in determining ungulate group sizes but in this study, habitat (woodland or open-riverine) did not have any significant effect on group size formation. In contrast, Bercovitch \& Berry (2010) found that solitary animals were more likely to range in riverine and thicket habitats than larger herds, whereas when excluding solitary individuals, the larger herds occupied more open habitats. Suggesting that foraging strategies are of primary importance for group formation. 


\section{CONCLUSION}

Overly, this study shows that giraffes have a wide range of group sizes that are related to the behavioural ecology of the species. The proportion of males to females portrays a negative relationship that has also been found in previous studies on Serengeti ecosystem such as among ostrich (Struthio camelus), impala (Aepyceros melampus) and wildebeest (Connochaetus taurinus) (Magige et al., 2009; Okello \& Yerian, 2009). The number of females was found to be much higher than males, which indicates that more research should be conducted on the reproduction and survival of males to understand the factors behind these findings. The risk of illegal hunting also resulted in an increased level of vigilant individuals as did a group's presence in a wooded habitat. The Maasai giraffe (G. c. tippelskirchi.) has shown a declining population trend in the larger part of its distribution in Africa; therefore, more detailed studies, especially on the reproduction, movement patterns, genetics and threats to the Maasai giraffe in the Serengeti ecosystem are recommended. Research that is more detailed will help conservationists to understand the current status as well as the proper management of this elegant species, which is also the national emblem of Tanzania, to ensure its longterm survival.

\section{ACKNOWLEDGEMENTS}

We are grateful to the Norwegian government for funding this study through the quota scheme to pursue our study at the University of Science and Technology (NTNU). Furthermore, our sincere thanks to Tanzania Wildlife Research Institute (TAWIRI), Tanzania National Parks (TANAPA) and the Ngorongoro Conservation Area Authority (NCA) for allowing us to conduct this study. We would also like to extend our thanks to Bård G. Stokke, Frode Fossøy, Raihan Sarker, Mr. Elias Kalumbwa and Mr. Valentine Mwamba (the late) for their help in the field and fruitful discussions.

\section{REFERENCES}

Arcese, P. \& Sinclair, A. R. E. (1995). Serengeti in the context of worldwide conservation efforts. In Serengeti II (eds A.R.E. Sinclair \& P. Arcese), pp. 31- 45. Chicago: University of Chicago Press.

Beauchamp, G. (2003). Group-size effects on vigilance: A search for mechanisms. Behavioural Processes, 63, 111-121.

Bercovitch, F.B., Bashaw, M.J. \& del Castillo, S.M. (2006).Sociosexual behaviour, male mating tactics, and the reproductive cycle of giraffe Giraffa camelopardalis. Hormones and Behavior, 50, 314-321.

Bercovitch, F.B. \& Berry, P.S.M. (2010). Ecological determinants of herd size in the Thornicroft's giraffe of Zambia. African Journal of Ecology, 48, 962-971.

Berger, J. (1979). Predator harassment as a defensive strategy in ungulates. American Midland Naturalist, 102, 197-199.

Bergström, R. \& Skarpe, C. (1999). The abundance of large wild herbivores in a semi-arid savanna in relation to seasons, pans and livestock. African Journal of Ecology, 37, 12-26.

Breedlove, M. (2004). Social system of the giraffe (Girafa camelopardalis).

Brewer, K. (2008). Advantages and disadvantages of group living. pp. 1-44. Essex, UK: Orsett Psychological Services.

Bro-Jorgensen, J. \& Durant, S. M. (2003). Mating strategies of topi bulls: getting in the centre of attention. Animal Behaviour, 65, 585-594.

Buechner, H. K. \& Roth, H. D. (1974). Lek system in Uganda kob antelope. American Zoologist, $14,145-162$.

Buhalis, D. (2000). Marketing the competitive destination of the future. Tourism Management, 21, 97-116.

Cameron, E. Z. \& Du Toit, J. T. (2005). Social influences on vigilance behaviour in giraffes, 
Giraffa camelopardalis. Animal Behaviour, 69, 1337-1344.

Cant, M. A., English, S., Reeve, H. K. \& Field, J. (2006). Escalated conflict in a social hierarchy. Proceedings of the Royal Society B-Biological Sciences, 273, 2977-2984.

Caro, T. M. (2005). Antipredator defences in birds and mammals. London, UK: The University of Chicago Press.

Charlesworth, D. \& Willis, J. H. (2009). Fundamental concepts in genetics; The genetics of inbreeding depression. Nature Reviews Genetics, 10, 783-796.

Day, S.B., Bryant, E.H. \& Meffert, L.M. (2003) The influence of variable rates of inbreeding on fitness, environmental responsiveness, and evolutionary potential. Evolution, 57, 13141324.

Ebensperger, L. A., Hurtado, M. A. J. \& RamosJiliberto, R. (2006). Vigilance and collective detection of predators in degus (Octodon degus). Ethology, 112, 879-887.

Ezenwa, V. O. (2004). Host social behavior and parasitic infection: a multifactorial approach. Behavioral Ecology, 15, 446-454.

Fennessy, J. \& Brown, D. (2010). Giraffa camelopardalis. IUCN, Gland, Switzerland.

Ginnett, T.F. \& Demment, M.W. (1997). Sex differences in giraffe foraging behaviour at two spatial scales. Oecologia, 110, 291-300.

Hayward, M. W. \& Kerley, G. I. H. (2005). Prey preferences of the lion (Panthera leo). Journal of Zoology, London, 267, 309-322.

Holmern, T., Johannesen, A. B., Mbaruka, J., Mkama, S. Y., Muya, J. \& Røskaft, E. (2004). Human-wildlife conflicts and hunting in the western Serengeti, Tanzania. Trondheim, Norway: Norwegian Institute of Nature Reseach.

Holmern, T., Mkama, S.Y., Muya, J. \& Røskaft, E. (2006.) Intraspecific prey choice of bushmeat hunters outside the Serengeti National Park,
Tanzania: a preliminary analysis. African Zoology, 41, 81-87.

Kaltenborn, B. P., Nyahongo, J. W. \& Tingstad, K. M. (2005). The nature of hunting around the western corridor of Serengeti National Park, Tanzania. European Journal of Wildlife Research, 51, 213-222.

Kideghesho, J. R., Nyahongo, J. W., Hassan, S. N., Tarimo, T. C., \& Mbije, N. E. (2006). Factors and ecological impacts of wildlife habitat destruction in the Serengeti ecosystem in northern Tanzania. African Journal of Environmental Assessment and Management, 11, 17-32.

Kideghesho, J. R., Røskaft, E. \& Kaltenborn, B. P. (2007). Factors influencing conservation attitudes of local people in Western Serengeti, Tanzania. Biodiversity and Conservation, 16, 2213-2230.

Kimwaga, Z. A. (2014). An Overview of the Tourism Sub-Sector: Achievements, Challenges and Priorities for Financial year 2014/2015.Dar es Salaam: National College of Tourism, Bustani Campus

König, B. (1997). Cooperative care of young in mammals. Naturwissenschaften, 84, 95-104.

Krause, J. \& Ruxton, G. D. (2002). Living in groups. Oxford, UK Oxford University Press.

Krebs, C. J. (ed.) (2009). Ecology. San Francisco, CA: Pearson Benjamin Cummings.

Li, Z., Jiang, Z. \& Beauchamp, G. (2009) Vigilance in Przewalski's gazelle: effects of sex, predation risk and group size. Journal of Zoology, London, 277, 302-308.

Lian, X. M., Zhang, T. Z., Cao, Y. F., Su, J. P. \& Thirgood, S. (2007). Group size effects on foraging and vigilance in migratory Tibetan antelope. Behavioural Processes, 76, 192-197.

Lima, S.L. (1995). Back to the basis of antipredatory vigilance: the group-size effect. Animal Behaviour, 49, 11-20. 
Loe, L. E., Irvine, R. J., Bonenfant, C., Stien, A., Langvatn, R., Albon, S. D., Mysterud, A. \& Stenseth, N. C. (2006). Testing five hypotheses of sexual segregation in an arctic ungulate. Journal of Animal Ecology, 75, 485-496.

Magige, F., Holmern, T., Stokke, S., Mlingwa, C. \& Røskaft, E. (2009). Does illegal hunting affect density and behaviour of African grassland birds? A case study on ostrich (Struthio camelus). Biodiversity and Conservation, 18, 1361-1373.

Magige, F. J. (2008). The ecology and behaviour of the Maasai ostrich (Struthio camelus massaicus) in the Serengeti Ecosystem, Tanzania. PhD Thesis, Norwegian University of Science and Technology.

Marealle, W. N., Fossøy, F., Holmern, T., Stokke, B.G. \& Røskaft, E. (2010). Does illegal hunting skew Serengeti wildlife sex ratios? Wildlife Biology, 16, 419-429.

Mathot, K. J. \& Giraldeau, L. A. (2010). Withingroup relatedness can lead to higher levels of exploitation: a model and empirical test. Behavioural Ecology, 21, 843-850.

Ndibalema, V. G. \& Songorwa, A. N. (2007). Illegal meat hunting in Serengeti: dynamics in consumption and preferences. African Journal of Ecology, 46, 311-319.

Nefdt, R. J. C. \& Thirgood, S. J. (1997). Lekking, resource defense, and harassment in two subspecies of lechwe antelope. Behavioural Ecology, 8, 1-9.

Okello, M. M., Manka, S. G. \& D'Amour, D. E. (2008). The relative importance of large mammal species for tourism in Amboseli National Park, Kenya. Tourism Management, 29, 751-760.

Okello, M. M. \& Yerian, S. (2009). Tourist satisfaction in relation to attractions and implications for conservation in the protected areas of the Northern Circuit, Tanzania. Journal of Sustainable Tourism, 17, 605-625.

Owen-Smith, N. (2008). Changing vulnerability to predation related to season and sex in an
African Ungulate assemblage. Oikos, 117, 602610.

Owen-Smith, R. N. (1988) Megaherbivores. The influence of very large body size on ecology. Cambridge, UK: Cambridge University Press.

Periquet, S., Valeix, M., Loveridge, A. J., Madzikanda, H., Macdonald, D. W. \& Fritz, H. (2010). Individual vigilance of African herbivores while drinking: the role of immediate predation risk and context. Animal Behaviour, 79, 665-671.

Philipo, N. (2011). Visitor's Experience on Tourism Services and Facilities in Serengeti National Park. -An Attitudinal and Perception Assessment SENAPAll. Masters thesis, University of Klagenfurt.

Plessis, L., van der Merwe, P. \& Saayman, M. A. J. B. M. (2012). Environmental factors affecting tourists' experience in South African National Parks. African Journal of Business Management, 6, 2911-2912.

Pratt, D. M. \& Anderson, V. H. (1979). Giraffe cow-calf relationships and social-development of the calf in the Serengeti. Zeitschrift Fur Tierpsychologie-Journal of Comparative Ethnology, 51, 233-251.

Pratt, D. M. \& Anderson, V. H. (1982). Population, distribution, and behaviour of giraffe in the Arusha-National-Park, Tanzania. Journal of Natural History, 16, 481-489.

Pratt, D. M. \& Anderson, V. H. (1985). Giraffe social behaviour. Journal of Natural History, 19, 771-781.

Prins, H. H. T. \& Weyerhaeuser, F. J. (1987). Epidemics in populations of wild ruminants anthrax and impala, rinderpest and buffalo in Lake-Manyara National-Park, Tanzania. Oikos, 49, 28-38.

Pulliam, H. R. \& Caraco, T. (1984). Living in groups: Is there an optimal group size? In Behavioural Ecology an Evolutionary Approach (eds J.R. Krebs \& N.B. Davies), pp. 122-147. Oxford, England: Blackwell Publishing. 
Reynolds, T. D. (1983). Pronghorn responses to hunting coyotes. Great Basin Naturalist, 43, 88-92.

Sinclair, A. R. E. \& Arcese, P. (eds.) (1995). Serengeti II. Dynamics, management and conservation of an ecosystem. Chicago: The University of Chicago Press.

Sorensen, V. A. \& Taylor, D. (1995.) The effect of seasonal change on the group size, group composition, and activity budget of whitetailed deer, Odocoileus virginianus. Ohio Journal of Science, 5, 321-324.

TAWIRI (2010). Aerial census in the Serengeti ecosystem. Arusha: Tanzania Wildlife Research Institute.

Van der Jeugd, H. P. \& Prins, H. H. T. (2000). Movements and group structure of giraffe (Giraffa camelopardalis) in Lake Manyara National Park, Tanzania. Journal of Zoology, 251, 15-21.

Young, T. P. \& Isbell, L. A. (1991). Sex-differences in giraffe feeding ecology -Energetic and social constraints. Ethology, 87, 79-89. 